\title{
Giant Pedunculated Lipoma Over Left Upper Limb: An Unusual Case Report
}

\author{
Harsh Rajeev Mehta ${ }^{1}$, Payal Salvi ${ }^{1}$, Sarojini P Jadhav ${ }^{2 *}$ and Suresh R Harbade ${ }^{3}$ \\ ${ }^{1}$ Junior resident, general surgery, India \\ ${ }^{2}$ Professor and head, Department of General Surgery, India \\ ${ }^{3}$ Associate Professor, Department of General Surgery, India \\ *Corresponding author: Sarojini P Jadhav, Professor and head, Department of General Surgery, India
}

\section{Introduction}

Lipomas are the most common mesenchymal tumours. They arise from primordial adipocytes and gradually increase in size with age. They usually develop as well-circumscribed, encapsulated masses that are freely mobile beneath the skin. Lipomas can occur in many locations all over the body, but most commonly in the subcutaneous tissue of the head, neck, shoulders and back. Lesions that are larger than $5 \mathrm{~cm}$ are termed as giant lipomas [1]. Giant lipomas of the upper extremity are rare and require an appropriate workup. This should be followed by adequate open surgical excision and repeat examination over time to monitor for recurrence.

\section{Case Report}

A 45-year-old gentleman presented with chief complaints of a large swelling over the left upper limb for 20 years. The swelling was initially small to begin with but increased gradually over the past 20 years to reach the present size. There were no associated complaints of weakness, numbness, difficulty in upper limb movements, loss of sensations or overlying skin colour changes. There was no history of any other swellings over the body. Patient was not having any associated comorbidities. On examination, a large pedunculated swelling of size $25 \mathrm{x} 15 \mathrm{~cm}$ over left arm extending from proximal one third to distal third of arm. No tenderness or local rise in temperature was present. Swelling was mobile with no fixity to skin, muscle or bone. Ultrasonography of local swelling was suggestive of lipoma. Fnac was done which was suggestive of lipoma. Patient underwent an elective open excisional surgery for the swelling under general anaesthesia. Patient was extubated and tolerated the procedure well. Histopathology reports were confirmatory for lipoma. Patient was discharged uneventfully (Figures 1-7).

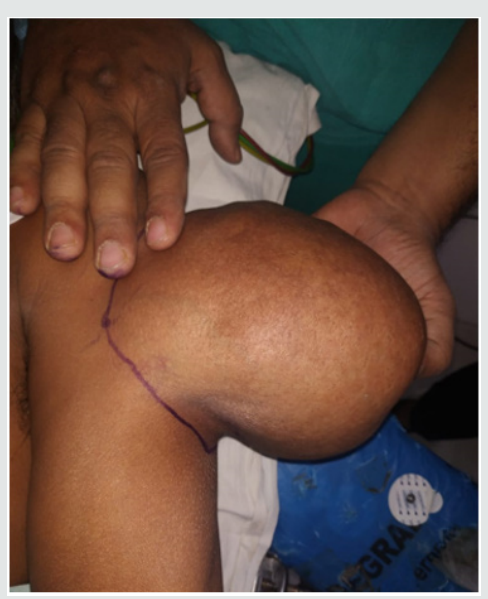

Figure 1: Lipoma over left upper limb. 


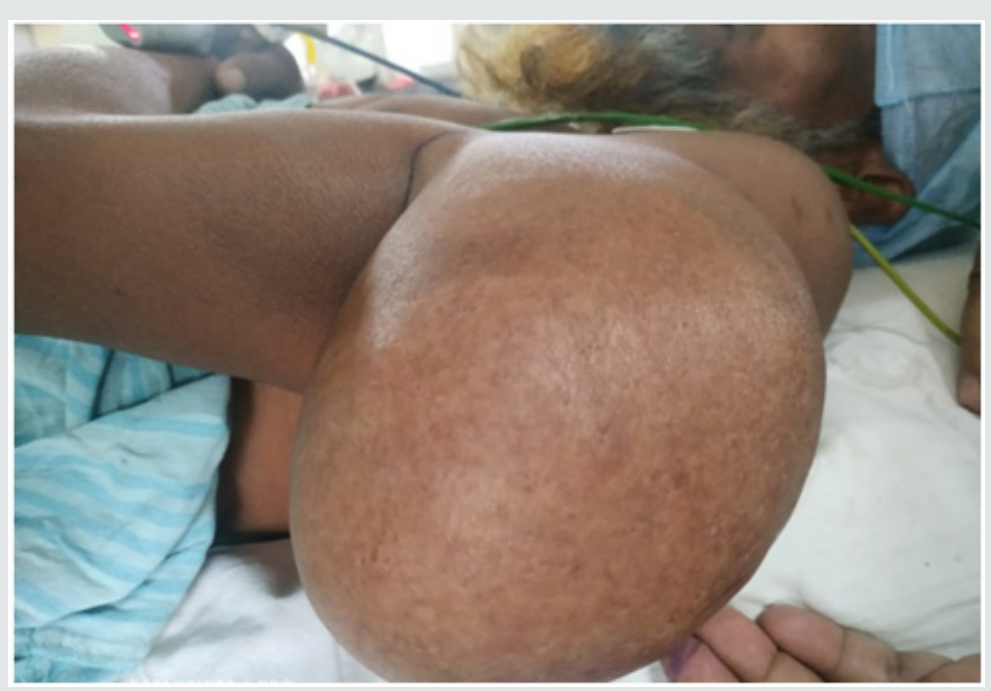

Figure 2: Lateral view

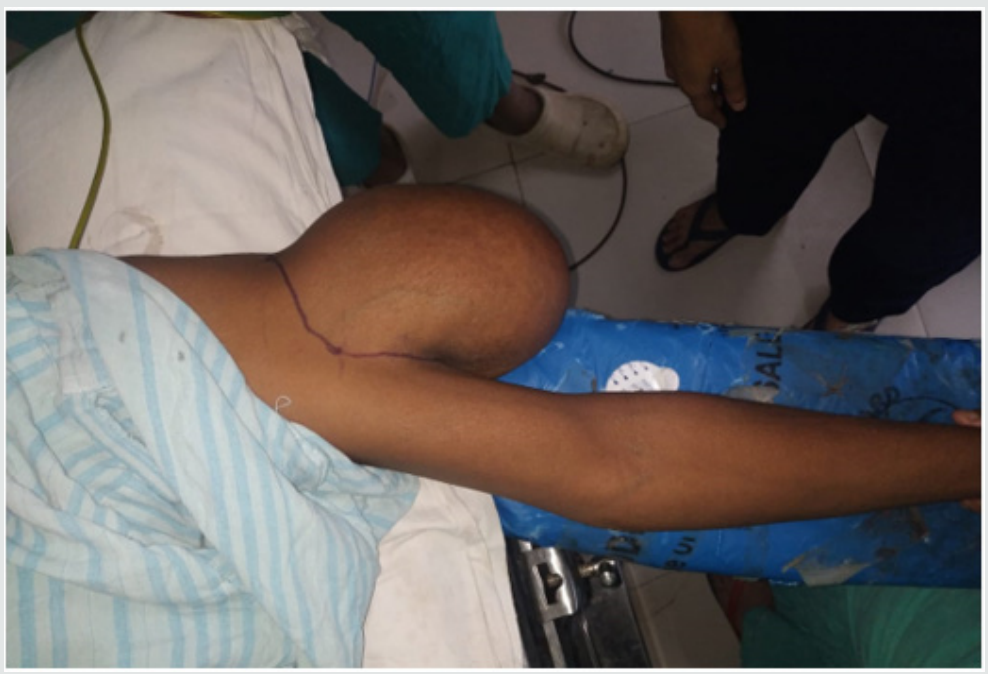

Figure 3: Size and extent of lipoma.

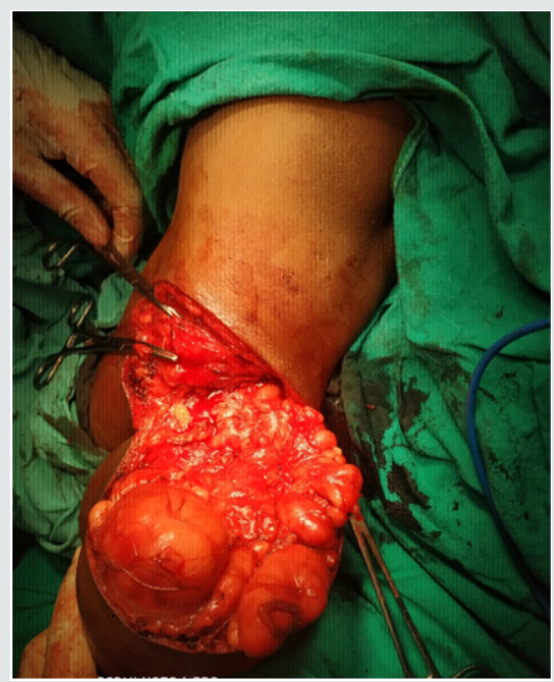

Figure 4: Intraoperative finding. 


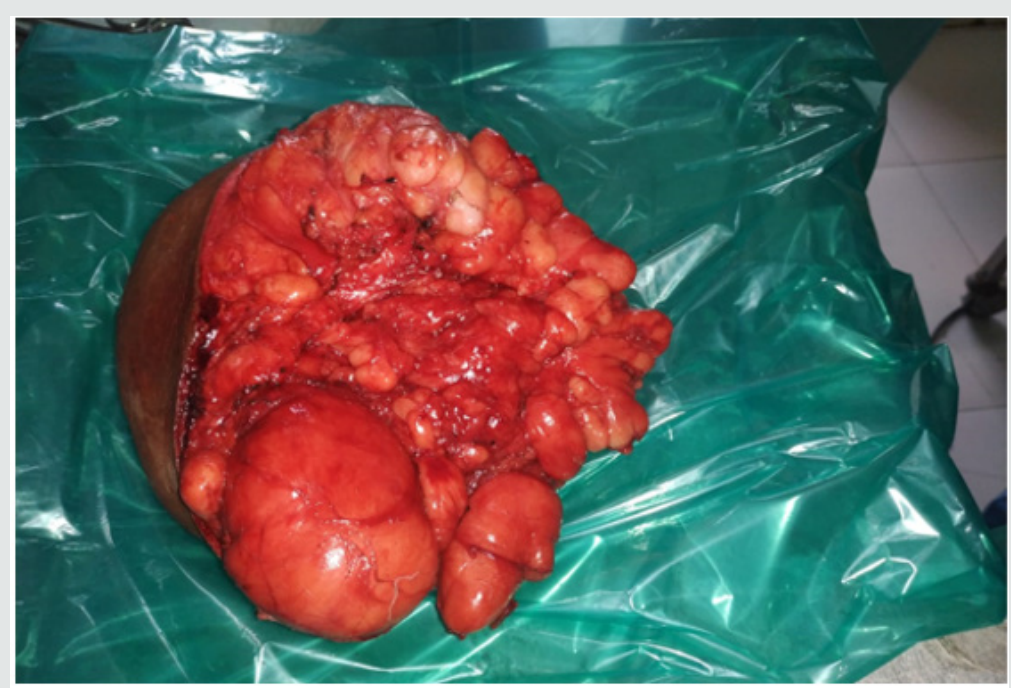

Figure 5: Excised specimen.

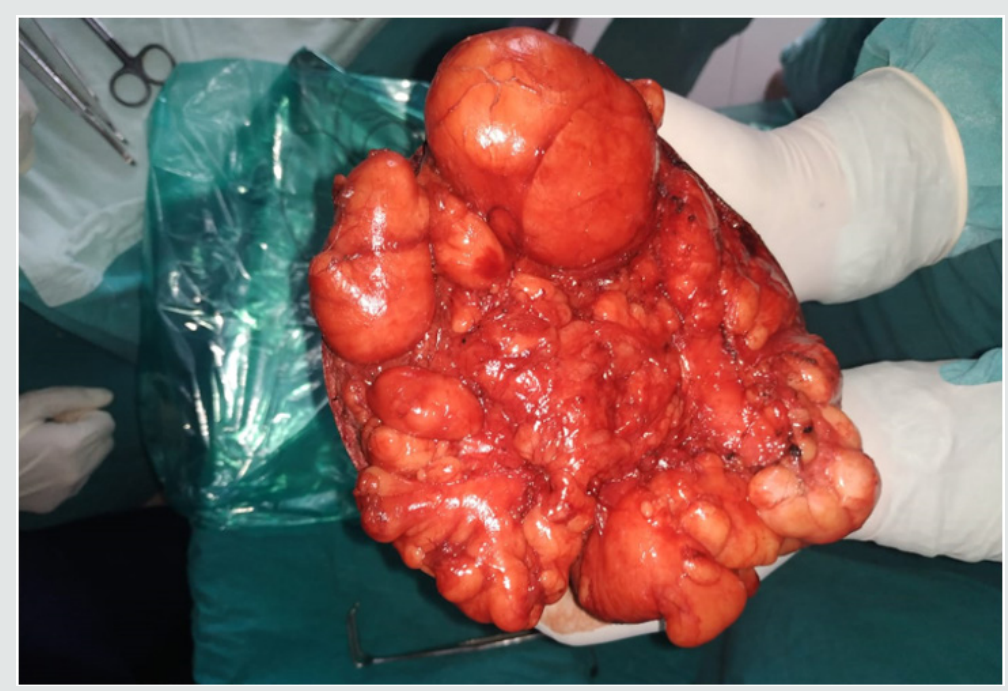

Figure 6: Gross specimen.

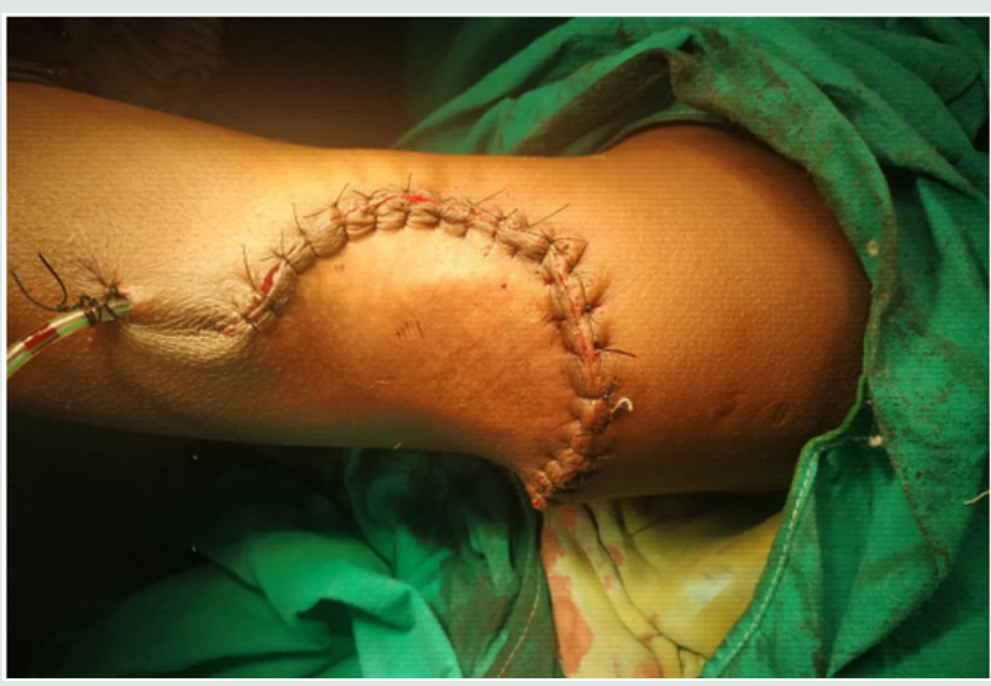

Figure 7: Postoperative status. 


\section{Discussion}

The standard management of giant lipomas is open excision [2]. A full histopathology report of the specimen is required to determine the possible need for any further treatment, as the main concern while evaluating a giant lipoma in the upper extremity is to rule out malignancy. Excisional surgery although being the standard treatment of giant lipomas also involves large incisions that may be associated with complication like infection, seroma or haematoma, as well as an unacceptable scar. Liposuction was employed for giant lipomas with added advantage of avoiding scar formation, but it may be complicated by skin puckering and dimpling as well as chances of recurrence [3]. It is suggested that if a fatty subcutaneous tumour is more than $10 \mathrm{~cm}$ in diameter and has shown a rapid growth in recent months, then the possibility of liposarcoma must be considered [4,5]. Clinically, the age of the patient and onset of symptoms must be thoroughly evaluated, and if possible, a magnetic resonance imaging or a tissue sample must be obtained in order to prove that the tumour is not malignant. Although if tumour is proved negative by these measures, it does not exclude the probability [6-8].

\section{Conclusion}

Giant lipomas are of size more than $5 \mathrm{~cm}$ and warrant a workup for malignancy. They rarely occur in upper limbs, unlike in our case, making it a rare finding. All lipomas in the upper extremities measuring larger than $5 \mathrm{~cm}$ in a single dimension should be surgically removed due to malignant potential.

\section{References}

1. Allen B, Rader C, Babigian A (2007) Giant lipomas of the upper extremity. Canadian Journal of Plastic Surgery 15(3): 141-144.

2. Higgs PE, Young VL, Schuster R, Weeks PM (1993) Giant lipomas of the hand and forearm. South Med J 86: 887-890.

3. Terzioglu A, Tuncali D, Yuksel A, Bingul F, Aslan G (2004) Giant lipomas: a series of 12 consecutive cases and a giant liposarcoma of the thigh. Dermatologic surgery 30(3): 463-467.

4. Celik C, Karakousis CP, Moore R, Holyoke ED (1980) Liposarcomas: prognosis and management. J Surg Oncol 14(3): 245-249.

5. Orson GG, Sim FH, Reiman HM, Taylor WF (1987) Liposarcoma of the musculoskeletal system. Cancer 60(6): 1362-1370.

6. Martin HS (1928) Massive lipoma of subcutaneous tissue of back: case report. JAMA 90: 2013-2015.

7. Deutsch AA, Bachar A, Reiss R (1984) Hemipelvectomy for liposarcoma: an unusual case and course. Post Med J 60(699): 70-72.

8. Sundaram M, Baran G, Merenda G, McDonald DJ (1990) Myxoid liposarcoma: magnetic resonance imaging appearances with clinical and histological correlation. Skeletal Radiol 19: 359-362.
This work is licensed under Creative Commons Attribution 4.0 License

To Submit Your Article Click Here: Submit Article
DOI: $10.32474 /$ GJAPM.2020.03.000151

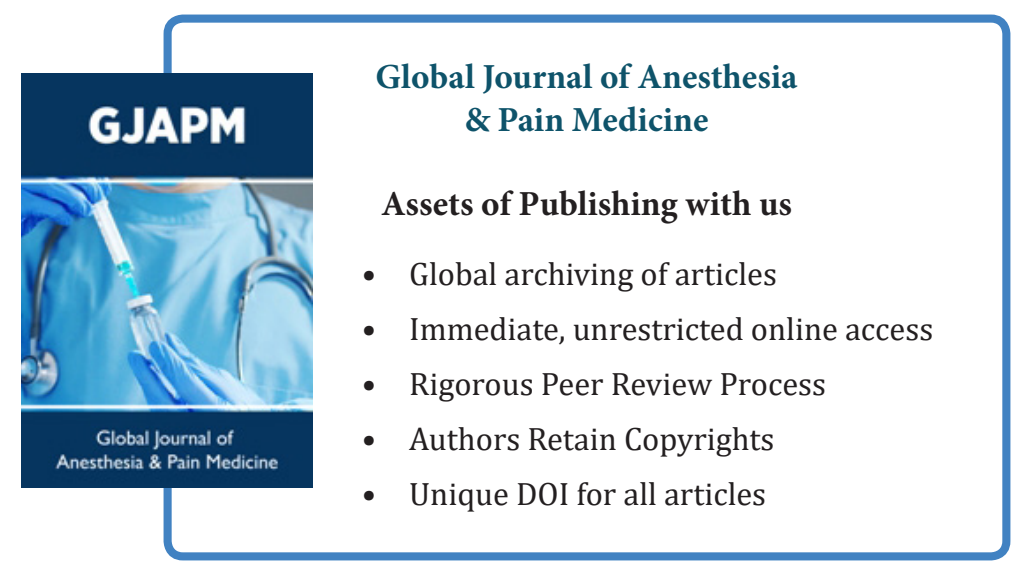

